\title{
WEAR BEHAVIOR OF AL 7075/FA/SIC HYBRID COMPOSITES
}

\author{
U. S. RAMAKANTH ${ }^{1} \&$ PUTTI. SRINIVASA RAO ${ }^{2}$ \\ ${ }^{I}$ Research Scholar, Department of Mechanical Engineering, Andhra University, \\ Visakhapatnam, Andhra Pradesh, India \\ ${ }^{2}$ Professor, Department of Mechanical Engineering, Andhra University, \\ Visakhapatnam, Andhra Pradesh, India
}

\begin{abstract}
This research examined the influence of sic and fly ash on the wear behavior of Aluminum 7075/5 and weight percentage of hybrid complex. Aluminum alloy 7075 strengthened with sic-fly ash were examined. The effectiveness of integration of sic in the composite for obtaining wear reduction is investigated in this study. Using under stir casting route, the composites were made-up. Ceramic elements were incorporated into aluminum alloy matrix along with solid lubricating materials to improve the friction coefficient and to achieve the decrease in both wear resistance. With 5 and 10 weight percentage of sic /fly ash particles, the Aluminum 7075/fly ash/sic hybrid compound was made. The wear properties of the hybrid composites including sic expressed the superior properties of wear-resistance.
\end{abstract}

KEYWORDS: Wear Rate, Al7075, Sic, Fly Ash, Hybrid Composite \& Sliding Speed

Received: Jan 15, 2019; Accepted: Feb 05, 2019; Published: Feb 27, 2019; Paper Id.: IJMPERDAPR201932

\section{INTRODUCTION}

Wear is the gradual material loss due to relative motion among two surfaces. The damage to wear may occur in the form of a localized plastic deformation or micro-cracks. Wear includes the characteristics of the engineering system and it depends on sliding speed, applied load, sliding distance, hardness, temperature, presence of foreign material and the experimental condition, and it is not intrinsic material property. It is a significant phenomenon that happens with reinforcement of hard particles at a materials interface metal matrix composites (MMCs), which offer wear resistance and superior performance. Aluminum based metal matrix composites are very valuable to the new materials field for the applications of high-performance tribology. Aluminum based composites are used increasingly in marine, aerospace and automobile and mineral processing industries due to their good wear resistance, specific strength, lower coefficient of thermal expansion and higher thermal conductivity. The reinforced materials that are widely used for the composite are aluminum oxide (Al2O3), silicon carbide (Sic) and graphite in the form of whiskers or particles. Normally, aluminum matrix composites are fabricated by powder metallurgy route and liquid casting technique. The particulates are well distributed mechanically before solidification and casting over the liquid metal in the liquid casting technique. Typically, these methods are cost effective. To study the effectiveness of reinforcements of fly ash and sic mixed with Aluminum 7075 at different weight percentage, the wear rate was examined in the present study. 


\section{PREPARING OF SPECIMENS}

Figure 1.1 shows the wear test specimens that are prepared from the composite castings and alloy in the dimensions of $\langle\gg 30 \mathrm{~mm}$ and $4 \mathrm{mmlength}$ by wire cut EDM process. The test samples were polished with emery papers prior to testing, and cleaned with acetone, dried.

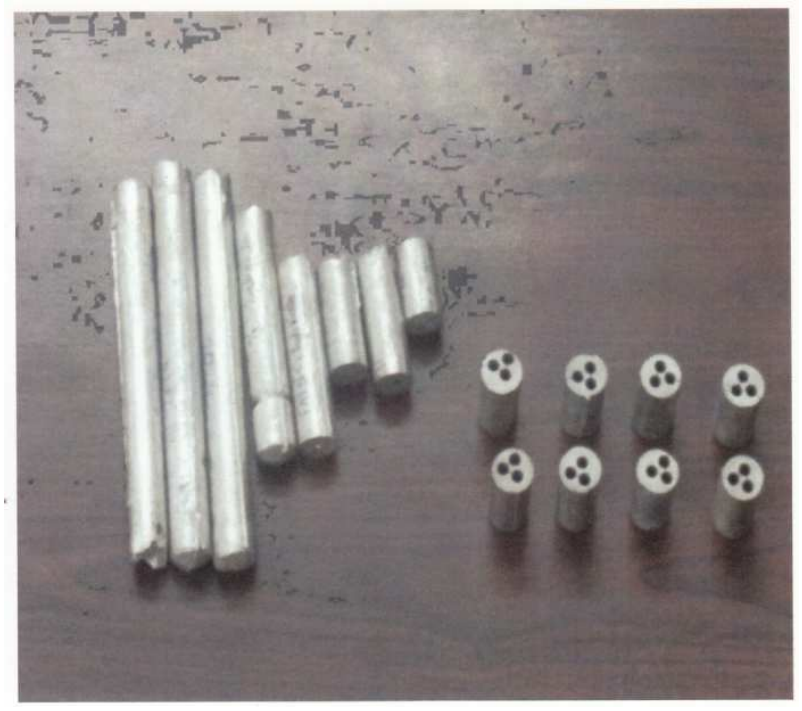

Figure 1.1: Shows Wear Test Specimens

\section{CONDUCTING OF DRYSLIDING WEAR TEST}

Under ambient condition, dry sliding wear tests are performed on a pin- on- disc apparatus, by tilting the cylindrical pin samples against the hardened steel disc surface. The disc is crushed to a flat surface finish and transformed for each test. Considering three levels and three parameters, the dry sliding wear tests are performed. Three independent parameters to be considered in this research are sliding time, load and reinforcement. Among these, the process parameters are load and sliding time, and reinforcement is the material dependent parameter.

\section{RESULTS AND DISCUSSIONS ON WEAR}

The sliding wear behavior of A7075 alloy and A7075 alloy-fly ash and SiC particulate composites are shown in the figure $1.2 \mathrm{a}$ and b. $0.5 \mathrm{Kgf}$ of load has been applied. For a period of 15 minutes, the wear test was conducted with track velocity of $2.0 \mathrm{~m} / \mathrm{sec}$ at the sliding speed of $640 \mathrm{rpm}$ on a steel disc with $120 \mathrm{~mm}$ track diameter. It is evident from all the results that the resistances increase with the reinforcement content increment. The amount of present particle toughens the matrix with increasing fly ash and $\mathrm{SiC}$ particulate content. Hence, the observation was more wear resistance. The MMC sunder went large wears with lower weight fraction soffly ash and SiC particulate, and the wear increases with time linearly. Higher wear is exhibited by the base metal, and the lower wear is showed by MMCs with 10 percentage reinforcements. The reason for the lower wear losses for composites compared to base alloy is the presence of SiC particulate and fly ash in Aluminum alloy matrix. With increasing normal load, the amount of wear increases. MMCs underwent a transition with increasing normal load from mild to severe wear. 

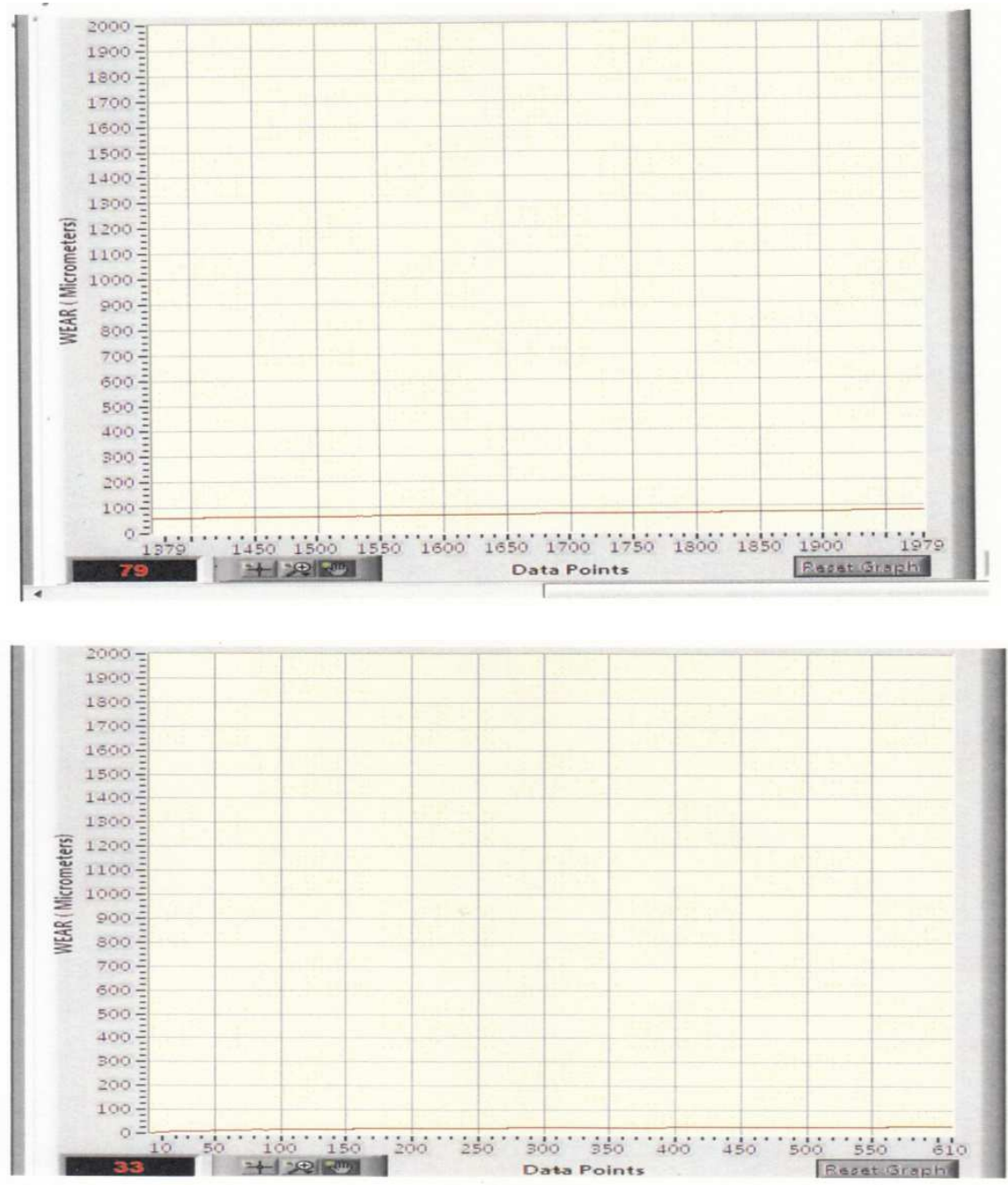

Figure 1.2 a: A 7075 Alloy Reinforced with $10 \%$ Fly Ash/SiC Particulates Showing the Amount of Wear as a Function of Sliding Times for an Applied Load of 0.5kg (Process Parameters: Speed: 640rpm, Time: 45min, Track dia: 70mm) b) A7075/5\% Composite

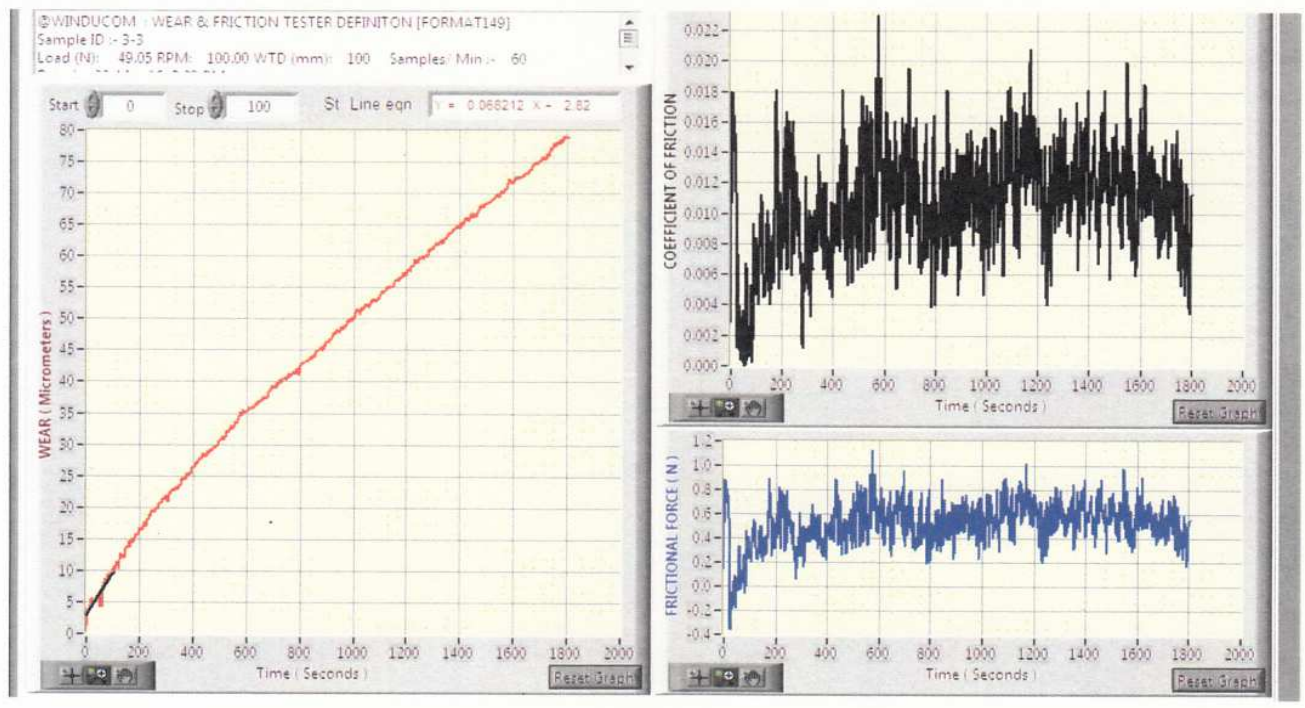

(a) 


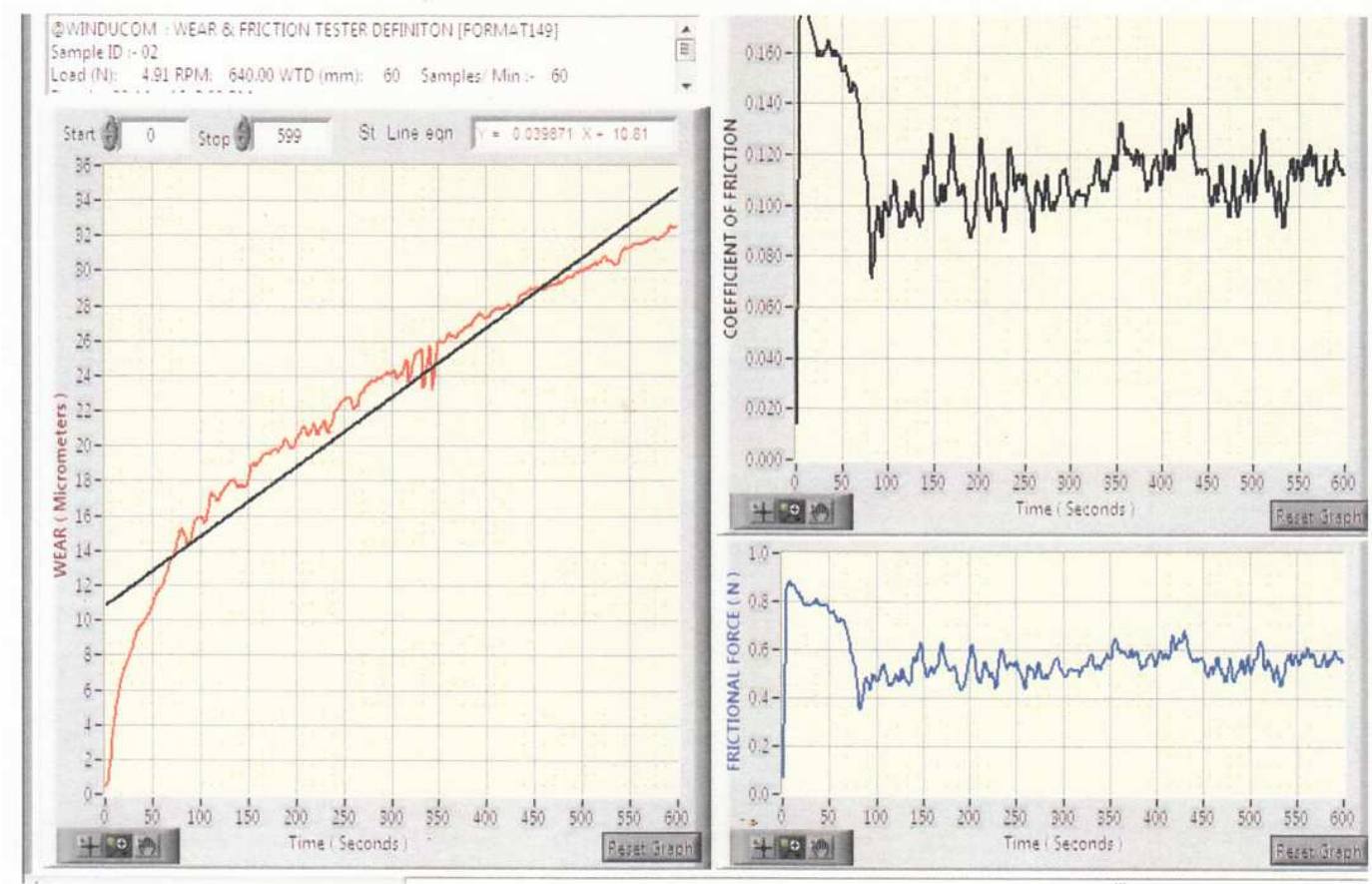

(b)

Figure 1.3a: A7075 Alloy Showing the Frictional Force as a Function of Sliding Times for an applied Load of 0.5kg (Process Parameters: Speed: 640rpm, Time: 45min, Track dia: 70mm).b) A7075/10\% Composite

It is portrayed from figure 1.3 A7075 alloy displaying the frictional force for an applied load of $0.5 \mathrm{~kg}$ as a function of sliding times. The frictional force inclines to reduce with the accumulation of fly as hand SiC particulates to the base alloy.

\section{EFFECT OF LOAD ON COEFFICIENT OF FRICTION (M)}

Figure 1.4 displays the change in the friction coefficient $(\mu)$ with varying loads for the alloy and composites. For both alloy and the composites, $\mu$ declined with growing applied weight. With increasing rein for cement content, it also decreased.

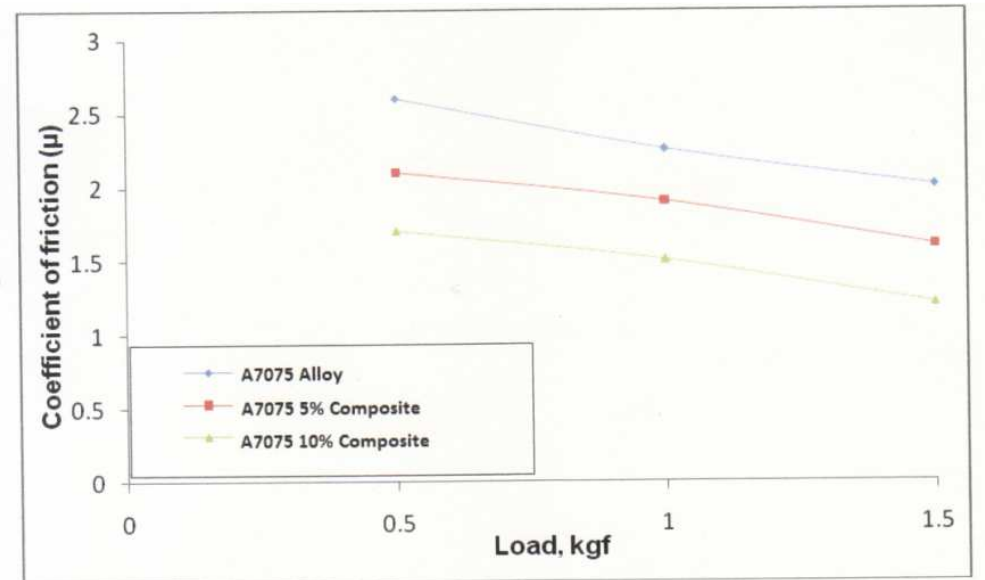

Figure 1.4: Variation of Coefficient of Friction $(\mathrm{J} . . \mathrm{l})$ as a Function of Load (a) $0.5 \mathrm{Kgf}$ (b) $1.0 \mathrm{Kgf}$ (c) $1.5 \mathrm{Kgf}$ 
From figure 1.4, i t is shown that A7075 alloy screening the frictional force as a function of sliding times for an applied load of $0.5 \mathrm{~kg}$. With the addition of $\mathrm{SiC}$ particulates and fly ash to the base alloy, the frictional force tends to decrease.

\section{EFFECT OF LOAD ON WEAR RATE}

Figure 1.5 shows the difference between wear rate of alloy and the composites with loads of 0.5, 1.0, and 1.5 Kgf. It was seen that the wear rate improved with load increase.

\section{EFFECT OF SLIDING DISTANCE ON WEAR RATE}

Figure 1.6 displays the effect of sliding distance on wear rate of the composites and alloy. Wear rate declined with the increase in sliding distance, at all loads. Both matrix and the rein for cement were in contact at initial stages of testing with the disc resulting high coefficient and high wear rate of friction values.

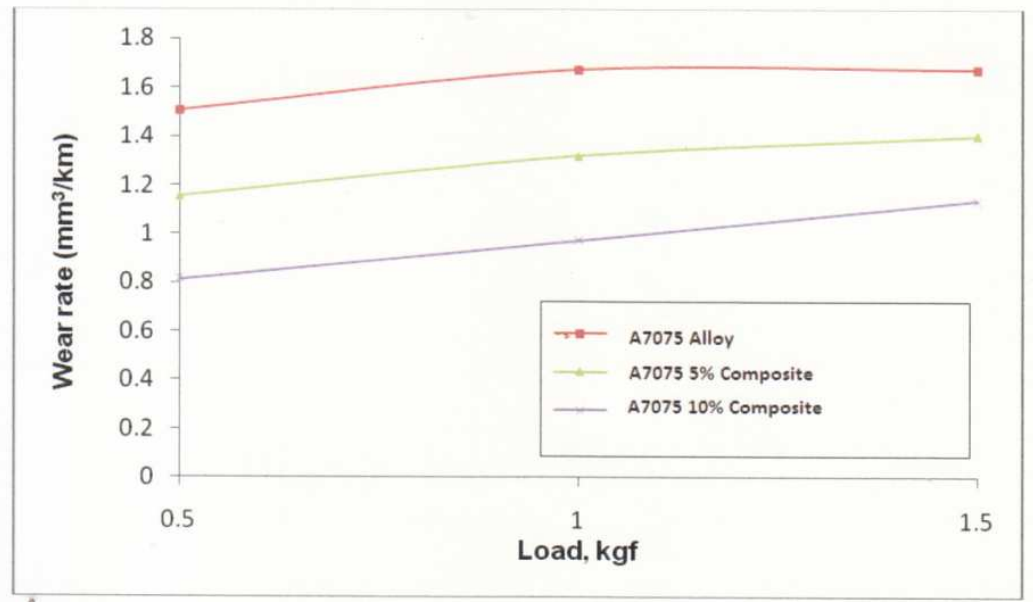

Figure 1.5: Wear Rate of Alloy and Composites with Load (Sliding Distance=2.lkm)

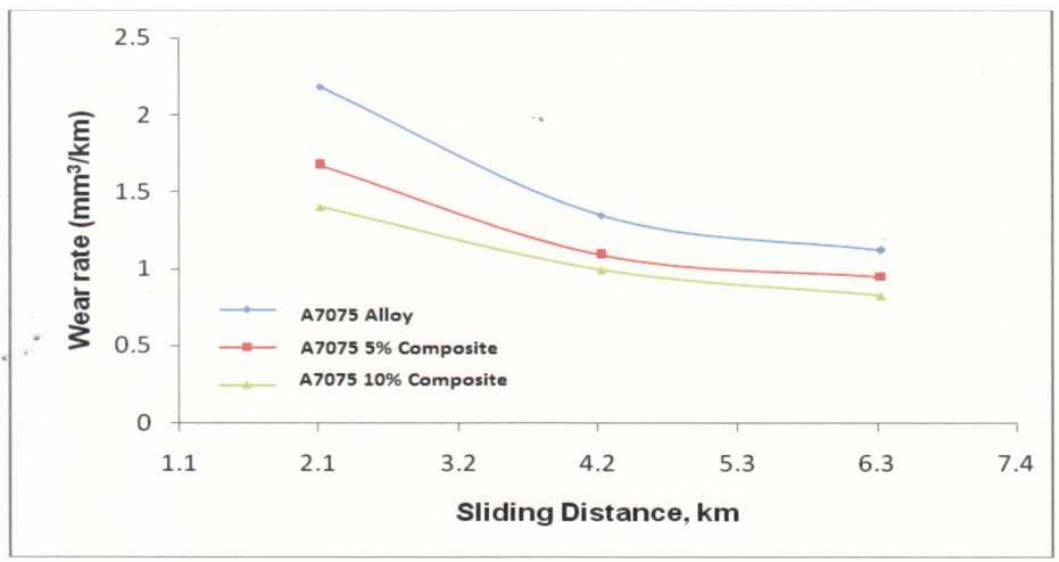

Figure 1.6: Variation of Wear Rate as a Function of Sliding Distances of a 7075 Alloy and Fly Ash and sic particles Reinforced Composites at Normal Load of $1.5 \mathrm{Kgf}$

\section{CONCLUSIONS}

With increase in time /sliding distance, the wear rate decreases, and this proves that the matrix has advised, and particulates were taking the weight, leading in reduced contact area (decrease in $\mu$ ) and offering more wear resistance. 
This is true with reduced $\mu$ values at increasing rein for cement contents. Figured is plays there in for cement banding nature showing un remitting rein for cements supply to the connection area, even when the particulate which was in connection with the rotating disc, either pulled off or worn out. This conversation goes good further, due to increased area of rein for cement at decreased wear rate at the contact area. The same description is good with growing descending distance, as well.

\section{REFERENCES}

1. Yllmaz O, Buytoz S. Abrasive wear of Al2O3-reinforced aluminium-based MMCs. Compos Sci Technol 2001;61:2381-92. Hassan AM, Alrashdan A, Hayajneh MT, Mayyas AT. Wear behavior of Al-Mg-Cu-based composites containing SiC particles. Tribol Int 2009;42:1230-8.

2. Gui M, Kang SB. Dry sliding wear behavior of plasmasprayed aluminum hybrid composite coatings. Metall Mater Trans A 2001;32A:2383-92

3. Tang F, Wu X, Ge S, Ye J, Zhu H, Hagiwara M, Schoenung JM. Dry sliding friction and wear properties of B4C particulatereinforced Al-5083 matrix composites Wear 2008;264:555-61.

4. Zhan Y, Zhang G. Graphite and SiC hybrid particles reinforced copper composite and its tribological characteristic. J Mater Sci Lett 2003;22:1087-9.

5. Leng J, Jiang $L, W u G$, Tian S, Chen G. Effect of graphite particle reinforcement on dry sliding wear of SiC/Gr/Al composites. Rare Met Mater Eng 2009;38:1894-8

6. Ghosh, S. Static Behavior of Poly (Acrylic Acid) Oligomer Stabilized Super Paramagnetic Ferro-Fluid in Seven and Thirteen Axial Grooves Journal Bearing.

7. Ramesh CS, Keshavamurthy R, Channabasappa BH. Friction and wear behavior of Ni-P coated Si3N4 reinforced Al6061 composites. Tribol Int 2001;43:623-34

8. Tjong SC, Tam KF. Mechanical and thermal expansion behavior of hipped aluminum-TiB2 composites. Mater Chem Phys 2006;97:91-7

9. William C, Harrigan J. Commercial processing of metal matrix composites Mater Sci Eng A 1998;244:75-9.

10. Akhlaghi F, Lajevardi A, Maghanaki HM. Effects of casting temperature on the microstructure and wear resistance of compocast A356/SiCp composites: a comparison between SS and SL routes. J Mater Process Technol 2004;155- 156:187480.

11. Erfan, O. S. A. M. A., El-Nasr, A., BA, A., \& Al-mufadi, F. (2014). Erosion-corrosion behavior of AA 6066 aluminum alloy. IJME, 3, 15-24.

12. Rosso M. Ceramic and metal matrix composites: routes and properties. J Mater Process Technol 2006;175:364-75

13. Seyed Reihani SM. Processing of squeeze cast Al6061-30 vol.\% Sic composites and their characterization. Mater Des 2006;27:216-22

14. Seyed Reihani SM. Processing of squeeze cast Al6061-30 vol.\% Sic composites and their characterization. Mater Des 2006;27:216-22

15. Estrada-Guel I, Carreno-Gallardo C, Mendoza-Ruiz DC. Graphite nanoparticle dispersion in 7075 aluminum alloy by means of mechanical alloying. J Alloys Compd 2009;483:173-7. 
16. Alhamdan, A., Sorour, H., Abdelkarim, D., \& Younis, M. Creep-Recovery Behavior For Eight Dates Cultivars At Two Different Maturity Stages. Jha AK, Prasad SV, Upadhyaya GS. Dry sliding wear of sintered 6061 aluminium alloy-graphite particle composites. Tribol Int 1989;22:321-8 
